\title{
Perilous Effects of Heavy Metals Contamination on Human Health
}

\author{
Naseem Zahra $^{* 1}$, Imran Kalim ${ }^{1}$, Minahil Mahmood ${ }^{2}$ and Nageen Naeem ${ }^{2}$ \\ ${ }^{1}$ Food and Biotechnology Research Centre, PCSIR Laboratories Complex, Ferozepur Road, Lahore-54600, Pakistan \\ ${ }^{2}$ Kinnaird College, Lahore, Pakistan. \\ *Corresponding Author Email: naseem.zahra1981@gmail.com \\ Received 02 March 2017, Revised 08 May 2017, Accepted 30 May 2017
}

\begin{abstract}
Heavy metals form a versatile group of high density elements that vary considerably in their biological roles and chemical properties. Although many heavy metals are essential trace elements yet they have long been recognized as environmental pollutants due their toxic effects. Increased industrialization, urbanization anthropogenic activities like mining, smelting and other agricultural activities have resulted in accumulation of heavy metals in the environment. Heavy metals such as nickel, cadmium, zinc, copper, mercury, arsenic and chromium are not easily degradable and tend to build up in soil. These heavy metals through various routes such as fish and plants make their way into the human body and are known to have serious detrimental effects on human health at elevated levels. The harmful effects of some important heavy metals on human health have been discussed.
\end{abstract}

Keywords: Heavy Metals, Pollution, Human Health, Metal contamination

\section{Introduction}

The term 'heavy metals' mostly refers to those metals having specific weights more than $5 \mathrm{~g} / \mathrm{cm}^{3}$ [1]. These metallic elements have relatively high density however; being a heavy metal has more to do with their chemical properties [6]. About 40 different metals have been put into this category and they are mostly found dispersed in rock formations. Increased industrialization and urbanization has led to increased levels of heavy metals in the environment. Heavy metals are most often found in soil and aquatic ecosystems and to a lesser extent in atmosphere as vapors. Certain heavy metals are required as trace nutrients by the animals and human body [2]. Heavy metals like $\mathrm{Zn}$ and $\mathrm{Cu}$ act either as activators for enzyme catalyzed reactions [3] or as prosthetic group in metalloproteins. As essential nutrients the heavy metals are required in redox reactions, electron transfer and also play structural roles in the metabolism of nucleic acids. Heavy metals like $\mathrm{Cd}$, $\mathrm{Hg}$ and As may prove to be fatal to metal sensitive enzymes and can lead to growth inhibition and even death. Based on coordination chemistry the heavy metals are regarded as class B metals that are non-essential and extremely toxic trace elements [4]. Heavy metals like $\mathrm{Ni}$ tend to accumulate in the environment and are difficult to break down or metabolize. These heavy metals are taken up by the primary producer and enter the ecological food chain and then reach to the consumer level. Heavy metal ions mainly enter the plant body through roots. Heavy metals may also be absorbed through leaves by particles deposited on the surfaces of the leaves. Plants in aquatic ecosystems are wholly exposed to the heavy metal ions dissolved in water. Human body may acquire heavy metals through direct inhalation or ingestion. Inhalation of heavy metals is mainly due to increased pollution resulting from excessive industrialization, urbanization, waste incineration and agricultural activities. Most of these heavy metals like $\mathrm{Cd}, \mathrm{Ni}$ and $\mathrm{Cr}$ are carcinogenic. They 
also pose a number of health hazards to humans such as $\mathrm{Cd}$ intake can lead to itai-itai disease, mercury accumulation may cause minimata disease and As intake through contaminated drinking water can cause poisoning [5]. Some of the important heavy metals include lead $(\mathrm{Pb})$, cadmium $(\mathrm{Cd})$, zinc ( $\mathrm{Zn})$, mercury (Hg), arsenic (As), chromium $(\mathrm{Cr})$, silver $(\mathrm{Ag})$, iron $(\mathrm{Fe})$, copper $(\mathrm{Cu})$ and elements of the platinum group.

Environment means the set of circumstances in which an organism or a group of organisms lives. It includes the combination of external physical conditions on which the growth and survival of an organism depends [6]. The environment includes the flora, fauna and the abiotic components and encompasses aquatic terrestrial and aerial habitats [7]. Any substance that has a deteriorating effect on the environment and impairs the quality of life can be regarded as a pollutant. Any such substance that is present in the environment beyond a certain limit can have serious and long lasting effects on human health [8].

\section{Biotoxicity of heavy metals}

The term 'biotoxicity' applies to the adverse effects of heavy metals on human body when consumed above the recommended levels. Heavy metals like lead, arsenic, cadmium, zinc, mercury, copper and aluminum exhibit some common signs of toxicity such as diarrhea, gastrointestinal disorders, tremors, vomiting, paralysis, stomatitis, depression, convulsion and pneumonia [9]. Heavy metal accumulation can have a wide range of effects from toxic, neurotoxic and carcinogenic to mutagenic or teratogenic [8]. Some of the most extensively studied effects of heavy metals are related to lead, cadmium, mercury and arsenic. The World Health Organization (WHO) regularly reviews the effects of these metals on human health. Despite the awareness about the harmful effects of heavy metals, the exposure to heavy metals continues to increase particularly in less developed countries.

\section{Sources of metal pollutants}

Several human activities are responsible for the continuous rise in the concentration of heavy metals in the environment. In the $20^{\text {th }}$ century cadmium emissions have increased dramatically because cadmium containing products are not recycled and are mostly thrown away with household waste. Cadmium compounds are also extensively used in rechargeable $\mathrm{Ni}-\mathrm{Cd}$ batteries. Cigarette smoke is the main source of exposure in smokers. In non-smokers, exposure mainly occurs through food contamination. Mercury exposure mainly occurs through food of which fish is the major source. Lead exposure occurs through air and food in equal proportions. Lead emissions mostly occur through petrol. Lead based paints and food containers are also sources of lead exposure. Arsenic exposure also occurs through food and drinking water. Arsenic exposure may also occur during occupational activities. Exposure to arsenic can be the source of skin cancer and lung cancer [10]. Fig. 1 shows routes of exposure of humans to heavy metals.

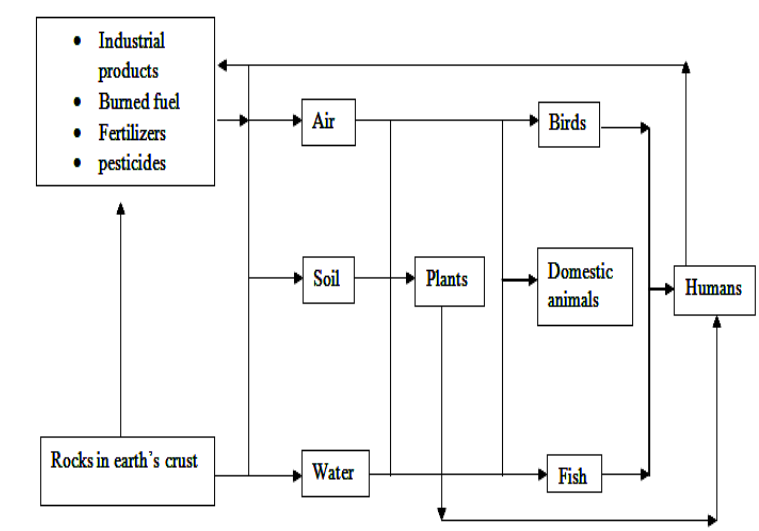

Figure 1. Exposure Routes of Heavy Metals to Humans

\section{Effects of copper accumulation on human health}

Copper is required in trace amounts by the human body for the functioning of many cellular enzymes. It acts as a catalytic cofactor for many enzymes catalyzing redox reactions, iron absorption, mitochondrial respiration, elastin crosslinking and scavenging of free radicals. However, excess of copper ions can cause damage to cellular components. Thus the amount of copper in the cell is maintained through a delicate balance between the uptake and efflux of copper ions [12]. Copper in the environment does not break down easily and can also prove to be bioaccumulative and toxic [25]. 
In vitro and cell culture studies show that copper is the cause of oxidative damage in cells. Oxidative damage is initiated due to chronic $\mathrm{Cu}$ overload resulting from accidents, environmental exposure and occupational hazards. This related oxidative damage has been shown to be the cause of neurodegenerative disorders and abnormal $\mathrm{Cu}$ metabolism [13].

It has been shown through experimental toxicity studies that consuming water with only 3 $\mathrm{mg}$ of $\mathrm{Cu}$ per liter can cause gastrointestinal problems with symptoms of nausea, diarrhea and vomiting [14]. Consuming excess of copper salts particularly copper sulfate can lead hepatic necrosis eventually causing death. However, no relationship between copper exposure and cancer has been established so far through epidemiological studies [15]. Hematological effects of copper may be more pronounced in people with deficiency of glucose-6-phosphate. However, the magnitude of risk is still unknown.

\section{Wilson's disease}

Accumulation of large amount of copper in liver, kidneys, brain and cornea leads to Wilson's disease. In this disease serum ceruloplasmin is low while unbound copper is elevated. Wilson's disease is characterized by high urinary excretion of copper. Excessive accumulation of copper in liver, kidneys and cornea are responsible for the clinical abnormalities of the disease. Accumulation of copper in the brain also occurs because of which the disease is sometimes referred to as the hepatolenticular degeneration. The biliary excretion of copper is also affected in such patients, which is believed to be the main cause of copper overload in the body. It has been found that liver is the main culprit in the disease because liver transplantation leads to a reversal of the abnormal copper metabolism. Genetic studies have revealed a linkage between Wilson's disease locus (WND) and the erythrocyte esterase enzyme D, showing that the defect might be in chromosome number 13 [16]. The abnormal gene product, WND protein, harness the energy stored in ATP and couples it to the transport of cations. It is thus responsible for the secretion of copper from the hepatocytes into the biliary canaliculus [17]. The clinical manifestations of the disease are highly variable which is explained through several different polymorphisms associated with the disease. Elevation in serum copper can lead to the initial diagnosis of the disease but it must be further confirmed through elevated amounts of copper in the liver and biopsy of the liver. Normal range of copper in liver is 15 to $55 \mu \mathrm{g} / \mathrm{g}$ while in Wilson's disease it may be as high as $300 \mu \mathrm{g} / \mathrm{g}$ [18].

\section{Indian childhood cirrhosis (ICC)}

ICC occurs mostly in children. It is characterized by a progressive liver disease causing jaundice. Diagnosis is usually done through liver biopsy. Two most important symptoms of the disease are brown orcein staining (copper) and intralobular fibrosis that ultimately leads to inflammation and portal cirrhosis [19]. The suspected cause of this disease is contamination of bottle feed with copper due to storage in brass vessels. However, epidemiologic studies have shown that an autosomal recessive genetic component is responsible for the disease. This has been suggested because of high consanguinity among the affected individuals and occurrence in families [20].

\section{Idiopathic copper toxicosis}

Also known as non-Indian childhood cirrhosis is known to occur in some western countries and is quite similar to ICC [15]. The largest number of cases has been reported in the Tyrol region in Austria. People of this region also stored milk in copper vessels. And replacement of these vessels has been shown to decrease the incidence of the disease. Cases of idiopathic copper toxicosis have also been reported in other parts of the world due to increased copper in drinking water [21].

Despite the fact that excess accumulation of copper causes adverse effects on human health, a deficiency of copper can also lead to oxidative damage in the cells. Many nutrients are known to interact with $\mathrm{Cu}$ and change its cellular effects. $\mathrm{Cu}$ induced damage in the cells can be protected through Vitamin E. Animal studies have shown 
that ascorbic acid is also protective against $\mathrm{Cu}$ induced damage. Excessive uptake of copper into the cells can also be prevented by consuming high amounts of zinc and ascorbic acid. $\mathrm{Cu}$ is removed from its binding site by zinc, thus preventing free radical formation. Certain other compounds such as beta-carotene, polyphenols and alpha-lipoic acid are also known to reduce oxidative damage caused by $\mathrm{Cu}$. However, much research is needed to completely elucidate the cellular effects of this potentially toxic but essential trace metal [13].

\section{Effects of lead accumulation on human health}

Lead is an important metal that is known to be highly toxic but is still used extensively in industries such as printing, pigment manufacturing, storage battery manufacturing, photographic materials and petrochemicals [26]. Lead contamination from these different industrial sources are significantly damaging to the environment. Lead through water can enter into the nutritional chain and pose serious threats to human health [27]. Exposure to inorganic lead can have toxic effects ranging from subtle forms to over effects [22]. Toxic effects of lead have been observed on a variety of organ systems. Most sensitive effects have been observed on the nervous system particularly in children and infants [23]. Occupational or accidental exposure in adults can lead to peripheral or chronic nephropathy. However, the most critical effect of lead toxicity in general public is hypertension. Most important indicator of lead exposure is its effect on the heme system, but mostly lead induced anemia is uncommon without other noticeable effects. Other organ system that may be affected due to lead exposure include gastrointestinal tract, skeletal and reproductive systems.

\section{Neurological and developmental effects in children}

Children with high lead exposure, typically at blood lead levels of $80 \mu \mathrm{g} / \mathrm{dL}$ or more, may lead to encephalopathy. Initial symptoms of lead encephalopathy include vomiting, lethargy, irritability, dizziness and loss of appetite. This can then lead to ataxia and a drop in the level of consciousness ultimately leading to coma and death of the patient. The pathological effects studied through autopsy include sever edema due to leakage of fluid from the brain capillaries. The neuronal cells tend to decrease in number while the glial cells increase. Recovery is slow and the patient often develops epilepsy, mental retardation and in some cases blindness also occurs due to optic neuropathy [24]. In the past 20 years many cross-sectional and prospective studies have been performed that relate the levels of lead in the blood during infancy and early childhood to psychological, cognitive and other behavioral outcomes [23]. Through these studies it has been reported that a 2 to 4 point decrease in IQ level occurs with every 10 micorgram-per-deciliter increase in blood lead level within 5 to $35 \mu \mathrm{g} / \mathrm{dL}$ range. However, a threshold cannot be defined through these studies. It is also difficult to state that increased lead exposure causes neurological deficits. No specific indicators of neurological effects of lead have yet been defined. Children with lower socioeconomic status show language deficit usually at 2 years of age, and it can be prevented through better academic facilities. High levels of lead in the blood during infancy and childhood can later be manifested in older age as smaller attention span, difficulty reading and failure to graduate [28]. In teenagers blood lead levels greater that $20 \mu \mathrm{g} / \mathrm{dL}$ have been associated with changes in hearing threshold [29]. Different degrees of abnormalities in neurobehaviour have been found in adults with occupational exposure to lead [30].

\section{Peripheral neuropathy}

The most important aspect of lead toxicity has been peripheral neuropathy particularly observed in house painter and other people with occupational exposure to lead as foot drop and wrist drop. Schwann cells in the nervous system degenerate due to excessive lead exposure leading to segmental demyelination and axonal disintegration. Sciatic and tibial nerves may also be affected but sensory nerves are less affected than the motor nerves. Motor nerve dysfunction can occur at blood lead levels as low as $40 \mu \mathrm{g} / \mathrm{dL}$ [31]. 


\section{Hematologic effects}

A number of hematologic effects have been associated with lead exposure. Microcytic and hypochromic red blood cells which are characteristic of iron deficiency have also been observed in lead induced anemia. In lead related anemia the reticulocytes also increase in number and have basophilic stippling. Two main causes of lead induced anemia are shorter life span of erythrocytes and impaired heme synthesis. The cell membrane of the erythrocytes becomes more fragile mechanically resulting in a shorter life span. This affect is also accompanied by an inhibition of $\mathrm{Na}$ and $\mathrm{K}$ dependent ATPases, however the exact biochemical mechanism is still unknown. Fig. 2 shows the effects of lead on the synthesis of heme. Most important effect seems to be on aminolevulinic acid dehydratase (ALA-D). coproporphyrin activity is also increased due to depression of coproporphyrin oxidase enzyme. The enzyme that is responsible for the incorporation of ferrous ion into the porphyrin ring i.e. ferrochelatase is also suppressed by lead. Since iron cannot be incorporated into porphyrin ring, the heme synthesis decreases. Thus more protoporphyrin is formed which is incorporated into the hemoglobin molecule in place of heme. When such red blood cells having protoporphyrin circulate in the blood, the zinc ion gets chelated at the place which is normally occupied by iron. This zinc containing protoporphyrin is fluorescent and can be used to diagnose lead toxicity. Since delta-aminolevulinic acid synthesis is controlled by negative feedback mechanism, less heme production leads to increase in the activity of this enzyme. Consequently more aminolevulinic acid (ALA) is produced while at the same time the activity of ALA-D decreases. This results in an increase in the urinary excretion and circulating blood levels of ALA. Studies on experimental animals indicate that lead exposure also increases the activity of heme oxygenase activity due to which bilirubin formation increases. The change in the activity of these enzymes occurs in a dose related manner with lead exposure, but anemia only occurs at very high levels of exposure [31].

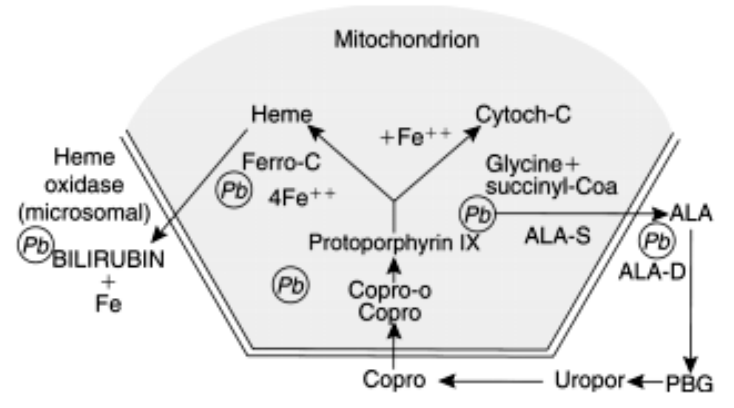

Figure 2. Effects of lead on heme synthesis [32]

\section{Renal toxicity}

One of the oldest known effects of lead exposure is lead nephropathy [33]. However, with the decrease in exposure of lead at work place and sensitive biological renal toxicity indicators, lead nephropathy is now decreasing. Lead nephropathy can be acute (reversible) or chronic (irreversible). In rodents lead has been recognized as a renal carcinogen. But it is not clear whether it is carcinogenic in humans or not. Acute lead nephropathy only causes morphological and functional alterations in the proximal tubular cells [34]. Clinical manifestations of lead nephrotoxicity are aminoaciduria, glycosuria and decrease in energy dependent ion functions. These functional changes are believed to be due to the effect of lead on mitochondrial respiration and phosphorylation. Studies involving animal models and biopsies of children suffering from lead toxicity indicate that the ultra-structure of mitochondria is impaired and they have distorted cristae. State III respiration has been shown to be decreased in rat models that were poisoned with lead. Treatment with a chelating agent can help reverse these changes. One of the most important microscopic features is the appearance of lead-protein complexes as inclusion bodies in the renal tubular cells. The protein in these complexes is acidic and mainly consists of aspartic and glutamic acids and small amounts of cystine. It has been lead has affinity for the carboxyl groups of the acidic amino acids [35]. In kidney cells grown in culture, lead forms inclusion bodies in the cytoplasm which then migrate to the nuclei [36]. When renal tubules degenerate and interstitial fibrosis increases in severity the inclusion bodies in the nuclei become less common. Chronic lead nephropathy is 
characterized by increase interstitial fibrosis which is associated with asymptomatic renal azotemia and decrease in the rate of glomerular filtration. No specific biomarker of lead renal toxicity is yet known. Chronic interstitial nephropathy occurs with prolonged exposure to blood lead levels more than $60 \mu \mathrm{g} / \mathrm{dL}$ [37].

Evidence also shows that lead impairs the heme-containing enzyme systems which are responsible for the metabolism of Vitamin D in the kidneys. The conversion of 25-hydroxyVitamin D to 1,25 dehydroxy-Vitamin $\mathrm{D}$ requires a heme containing hydroxylase enzyme in the kidney. This reaction is essential for the synthesis of Vitamin D. Vitamin in turn is required for the absorption of calcium in the gastrointestinal tract [38].

\section{Gout nephropathy}

High lead exposure leading to gouty nephropathy has been known for a long time. The exact metabolic mechanism leading to raise in blood uric acid levels is not known. However, it has been observed that patients with both gout and renal diseases have more lead excretion than patients without gout but with lead induced renal diseases [39].

\section{Effects on cardiovascular system}

The relationship between lead exposure and hypertension is not yet fully established. There are contradictory results from many researches regarding a causal relationship between lead exposure and blood pressure. Changes in the plasma rennin and urinary kallikerin, changes in the calcium dependent functions of vascular smooth muscle cells due to reduced $\mathrm{Na} / \mathrm{K}$ ATPase activity, effects on $\mathrm{Na} / \mathrm{Ca}$ exchange pumps and alterations in response to catecholamines have been suspected as the possible mechanism for the effect of lead on blood pressure [31, 40].

\section{Immunotoxicity}

Studies have been performed on workers with occupational exposure to lead which indicate that lead is immunosuppressive. Lead may cause a decrease in the immunoglobulins and other components of the immune system. Polymorphonuclear lymphocutes may show changes in chemotaxis in workers with $33 \mu \mathrm{g} / \mathrm{dL}$ of blood lead levels [41]. Peripheral B-lymphocytes may also decrease in number [42].

\section{Effects on bone}

Skeletal mass including lead is regulated by four types of cells namely osteoblasts, osteoclasts, osteocytes and lining cells. These cells are essential for the formation of matrix, mineralization and resorption of bone. They from the lining of the mineralized bone matrix and also penetrate into it. Bone cell formation may be altered due to lead toxicity either directly or indirectly. The mechanisms that govern influx and efflux of calcium from bone such as calcitonin, parathyroid hormone, Vitamin D and other hormones influencing calcium metabolism are also thought to be responsible for the mobilization and retention of lead in bone [43]. Gastrointestinal absorption of calcium is also competed by lead [44]. Exchange can occur between the lead in bone and blood lead. It has been shown that lead in bone accounts for $45 \%$ to $70 \%$ of blood lead in women of childbearing age. Similarly almost same percentage of lead has been found in fetus which is thought to be originating from the maternal skeleton. Mobilization of lead from the bones also increases with pregnancy and lactation paralleled by an increase in blood lead during prenatal period [45].

\section{Reproductive effects}

Lead toxicity has also been found to be associated with sterility and deaths during the neonatal period [46]. Animal studies have revealed gametotoxic effects in both males and females. Workers having blood lead levels more than 60 $\mu \mathrm{g} / \mathrm{dL}$ show more chromosomal defects as indicated through clinical studies. Blood lead levels as low as $40 \mu \mathrm{g} / \mathrm{dL}$ can cause reduced sperm production, impairment of sperm motility and morphology [47]. Testicular endocrine function is also reduced in smelter workers with prolonged lead exposure [48]. 


\section{Birth outcomes}

It has been suggested that prenatal exposure to lead may increase the risk of preterm delivery. Gestational period and birth weight may also be reduced due to increase in the blood lead levels of the mother [49].

\section{Effects of cadmium accumulation on human health}

Cadmium is a highly toxic heavy metal and has been extensively used in pesticides, fungicides and herbicides. Through these routes cadmium can enter into the food chains and adversely affect humans and animals [50].

\section{Effects on kidney}

Cadmium is an environmental pollutant that is persistent and widely spread [51]. The accumulation of cadmium in body exhibits the most adverse effects on one of the most critical organs of the body i.e. kidney [52], by ingestion or by inhalation [53]. Kidney dysfunction occurs due to long time exposures of cadmium by a protein called metallothionein [54], which is responsible for carrying cadmium to the kidney and it also provides intracellular protection against toxicity of cadmium. As the effect occurs at low levels of exposure, so it is considered as a critical effect [55]. In humans, cadmium can cause a decrease in glomerular filtration rate and can also cause damage to renal proximal tubule.

Cadmium binds to serum albumin after gastrointestinal absorption and gets accumulated in liver. In liver it gets complexed with metallothionein-1, which has high affinity for cadmium. Thus the complex called Cdmetallothionein-1 reaches to the kidney and here it gets filtered and then accumulated in proximal tubule. The cells of proximal tubule carry transporters for bounded and free forms of cadmium and thus interfering with the functions of tubules [56]. Thus in kidney tubules, the amount of cadmium increases with increased life span. As a result the increased load of cadmium on kidney leads to the increased risk of kidney stones. Cadmium induced kidney damage has been correlated with urinary cadmium excretion. A degree of $4 \%$ renal tubular damage occurs due to the urinary excretion of $2.5 \mu \mathrm{g}$ cadmium per gram creatinine [57]. Fig. 3 shows cadmium handling in human body.

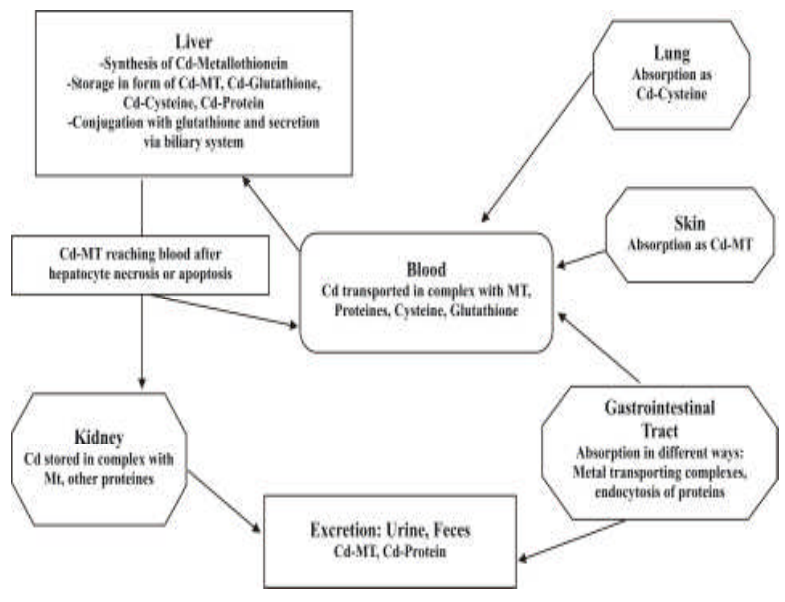

Figure 3. Cadmium handling in human body [77]

Cadmium is excreted through urine and feces [77].

Retinol-binding-protein (RBP), N-acetyl$\alpha$-D-glucosaminidase (NAG) and urinal excreted $\beta 2$-microglobulin are the primary biomarkers of kidney damage [58]. A study named ChinaCad-study showed that higher values for RBP and $\beta 2$-microglobulin are more prevalent in people with increased blood cadmium as compared to the people with normal values [59].

95\% of cadmium is taken up with drinks and food. $30 \mu \mathrm{g}$ additional intake of cadmium has been observed in an average smoker [60]. Factors such as low intakes of calcium, Vitamin D and trace elements such as copper and zinc can increase this amount [61]. Dietary cadmium intake increases by increased fiber diet [62]. Deficiency of iron is the most important metabolic factor for the uptake of cadmium. A study showed that there is $6 \%$ higher intake of cadmium in people with low iron stock as compared to those with balanced iron stock [63]. That is why people with iron deficit and anemia have higher cadmium resorption. In gastrointestinal tract, the expression of a metal ion transporter called DCT-1 is stimulated by low iron 
blood levels, which serves as a gate for resorption of cadmium [64].

\section{Effects on bone}

Studies of $20^{\text {th }}$ century showed a relation between bone damage and cadmium intoxication [65]. Cadmium affects the bone directly. Symptoms such as increased rate of osteoporosis, high rate of fractures, low bone mineralization and intense pain in bones come under a disease called Itai-Itai, is also associated with cadmium. A study on Japanese people showed that cadmium contaminated rice diet causes itai-itai disease [66]. Bone damage also occurs in people who work in cadmium polluted dust and fume [67].

\section{Effects on gastrointestinal tract}

Acute GI effects such as diarrhea etc. are caused by cadmium contaminated food intake [68]. Cadmium contaminated air inhalation severely affects respiratory system. Acute pneumonitis also occurs due to high concentration of cadmium fumes [69]. Cigarette smoke is the main source of cadmium intoxication. $40-60 \%$ of cadmium present in tobacco smoke is resorbed by human lungs. Generally smokers have 4-5 times cadmium blood levels as compared to non-smokers. A life-long smoker has $30 \mathrm{mg}$ of cadmium whereas a non-smoker has 15 $\mathrm{mg}$ of cadmium. "Acute respiratory distress syndrome" (ARDS) has been reported in workers who work in cadmium-containing fumes environment.

\section{Carcinogenicity}

Cadmium, a toxic heavy metal, is also responsible for causing cancer. Plastic and pigment stabilizers, mining, manufacturers of nickelcadmium batteries and metallurgy industry are responsible for causing cadmium pollution in environment. Food, water, cigarette smoke and air contaminations are the main sources of human intoxication. Cancers of lungs, testes and prostate have been associated with cadmium exposures in humans. Acute cadmium exposures cause harm to these organs.

\section{Other effects}

Chronic intoxication is related with emphysema, immune suppression, bone disorders, obstructive airway disease and irreversible renal failure. Cadmium also affects differentiation, proliferation and causes apoptosis at the cellular level. International Agency for Research on Cancer (IARC) has classified cadmium as a carcinogen. DNA damage and production of reactive oxygen species (ROS) result due to indirect effects of cadmium. Cadmium also interferes with DNA repair and reduces the functions of proteins that are responsible for antioxidant defenses [70].

Cadmium administration in animals causes tumors of multiple tissues or organs. Cells transformation also results due to cadmium exposure. Studies showed that a causal relation has been found between lung cancer and cadmium exposure. It causes cancer by many mechanisms such as oxidative stress induction, inhibition of DNA damage repair and apoptosis and aberrant gene expression. Some incidences have indicated that cadmium carcinogenesis is caused by oxidative stress due to its involvement in apoptosis, DNA damage repair inhibition and aberrant gene expression [71].

Cadmium is a very strong toxic heavy metal and in nature it can't be destroyed. It causes aberrant DNA methylation. Epigenetic effects of cadmium are DNA methylation reduction and low regulation of methyltransferases [72].

Some studies have shown that low level exposure to lead and cadmium may be responsible for causing hearing loss. As previously explained that exposure of cadmium causes apoptosis and changes the procedure of receptor cells present in inner ear thus resulting in increased auditory thresholds. Thus in order to avoid cadmium efforts should be done to reduce cadmium in environment [73].

Cadmium is present in higher concentrations in tobacco leaves and studies have revealed that cadmium level in human cataracts is much higher as compared to normal lenses [74]. Studies have shown that the increased presence of 
cadmium concentration in smokers is associated with cataracts presence. Cadmium concentration is higher in lenses and blood of smokers than nonsmokers. The cadmium accumulation in the lenses of smokers with cataracts is much higher as compared to non-smokers [75].

\section{Effects of arsenic accumulation in human body}

Arsenic is a global heavy metal present in low concentrations virtually everywhere, in rocks soil, air, and water [76]. Compounds of arsenic have been used in the treatment of trypanosomaiasis, amoebic dysentery, yaws and syphilis for at least a century. It is also used in the treatment of African sleeping sickness [77]. Fig. 4 shows exposure to arsenic via food stuffs and drinking water; Ingestion of arsenic causes arsenicosis and it occurs due to consumption of contaminated water for several years. Many studies have shown relationship of chronic arsenic exposure with chromosomal abnormalities, diabetes, carcinogenic effects, skin disorders, neurological diseases, hypertension, cerebrovascular events, cardiovascular diseases, blackfoot diseases and peripheral vascular disorders.

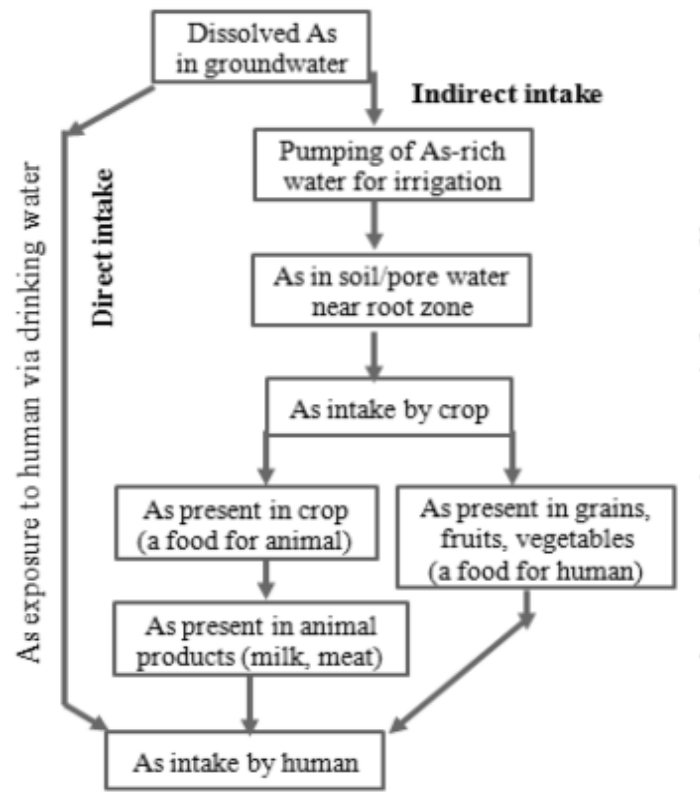

Figure 4. Exposure to arsenic via food stuffs and drinking water [84]

\section{Effects on skin}

Skin pigmentation developed abnormally in black brown color called melanosis, occurs due to drinking contaminated water having low arsenic concentrations. Keratosis is a disease in which soles and palms become thicken and as a result painful cracks appear due to arsenic contaminated water [78].

\section{Diabetes and arsenic}

Studies have found an association between type 2 diabetes and arsenic and the arsenic exposure over $50 \mu \mathrm{g} / \mathrm{L}$ in drinking water shows greater risk of type 2-diabetes. People who drink water having highest concentration of arsenic for a time period of more than ten years, are at greater risk of type 2-diabetes [79].

\section{Neurologic effects}

Arsenic exposure also causes neurological diseases. Methylated arsenic as well as inorganic arsenic accumulates in the pituitary and in many parts of brain. During development arsenic in high concentrations, a teratogen, crosses the placenta and causes defects in neural tubes and induce lying off growth. Ingestion of chronic arsenic causes mood disorders and changes intelligence measures. During childhood, exposure to arsenic causes change in cognitive function especially memory and learning [80]. According to researchers, there is a $0.4 \%$ decrease in IQ of children who have been exposed to arsenic [81].

\section{Anemia and arsenic}

A recent study done in Bangladesh showed that there is a relation between anemia and arsenic exposure. So the risk of anemia increases if the arsenic exposure increases, thus causing blunted development and growth [82]. In adults, exposure to arsenic causes poor grading in tests, poor spatial and visual skills exhibiting cognitive dysfunction showing early indications of Alzheimer disease [83]. Studies have proved that $10.6 \mu \mathrm{g} / \mathrm{L}$ of arsenic exposure has worse effects on cognitive assessment than individuals exposed to $6.5 \mu \mathrm{g} / \mathrm{L}$ [84]. 


\section{Effects on kidneys}

Arsenic accumulation also causes damage to kidneys. In kidneys, pentavalent arsenic gets converted into highly toxic and more soluble trivalent arsenic. In kidneys it causes damage to glomeruli, tubules and capillaries. Hematuria occurs due to the dilation of glomerular arterioles and proteinuria occurs due to the damaged proximal tubules. Severe arsenic poisoning causes dehydration and it increases the risk of renal failure. Acute tubular necrosis is caused by arsenic induced hemolysis.

\section{Other effects}

Low doses of arsenic inhalation causes heartburn, dry throat and mouth, moderate diarrhea, cramps and abdominal pains whereas ingestion of chronic arsenic in low dose produce colitis or gastritis and esophagitis without showing any symptoms of gastrointestinal irritation.

Studies done in Bangladesh, India and Chile have shown that there is a relation between non-malignant respiratory effects and arsenic ingestion. Studies from the regions that are affected with arsenic such as Argentina, Chile and Taiwan have shown increase in the death rate by lung cancer. Milton et. al, has demonstrated that there is a relation between chronic bronchitis and ingestion of chronic arsenic, in his cross sectional study done in Bangladesh.

Patients suffering from Blackfoot disease have increased death rates due to increased death rates by ischemic heart disease. Blackfoot disease occurs due to arsenic accumulation, is a peripheral atherosclerosis in which the lower limb's blood vessels get severely damaged leading to dry gangrene. Recent reports have showed that health effects including polyneuropathy, bronchitis, nasal septum perforation, noncirrhotic portal fibrosis and peripheral vascular disease occur due to high arsenic levels in drinking water.

In addition to lung cancer, there is an increased risk of bladder, colon, kidney, liver and skin cancer due to arsenic exposure as summarized in fig. 5 [85]. Studies done in Chile have reported that $50 \mu \mathrm{g} / \mathrm{L}$ arsenic in drinking water causes skin cancer as well as internal organs cancer, if used for longer durations [76].

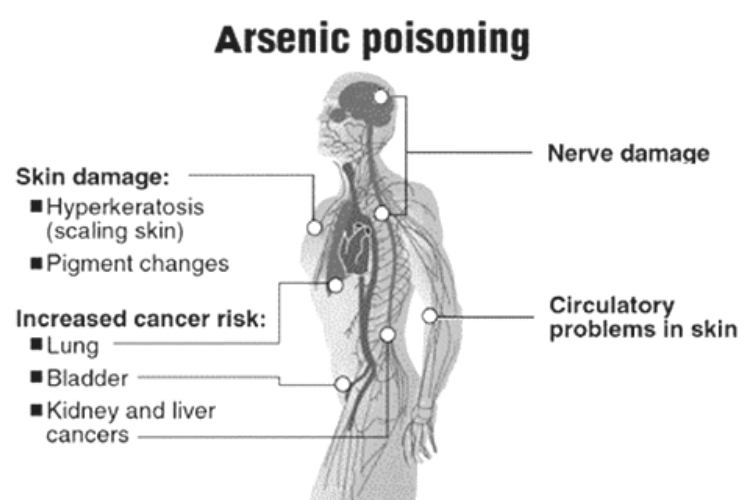

Figure 5. Arsenic poisoning in humans

\section{Effects of zinc accumulation on human health}

Zinc is relatively less toxic to humans as compared to other toxic heavy metals [86]. 2-3 g of zinc is present in human body and our bones and muscles contain nearly $90 \%$ of zinc [87]. Some estimable zinc concentrations are present in other organs such as pancreas, heart, brain, lung, skin, kidney, liver, prostate and the gastrointestinal tract [88]. If the level of zinc in drinking water exceeds $5 \mathrm{mg} / \mathrm{L}$ then it may cause brain, gonads, liver and respiratory disorders [89]. In nucleus i.e. on cellular level, $30-40 \%$ of zinc is present and in the cytosol $50 \%$ of zinc is located and the rest of it is found in membranes [90].

Zinc enters into the human body by three main routes; i.e. by ingestion, via skin or by inhalation [91]. Fig. 6 shows the comparison between effects of zinc deficiency and zinc excess [92].

The ingestion of zinc in small amounts is necessary for survival. RDA has approved 8 $\mathrm{mg} / \mathrm{day}$ of zinc for women and $11 \mathrm{mg}$ /day for men [93]. If taken in greater amount such as $225-400$ $\mathrm{mg}$, then it induces vomiting, nausea, abdominal pain, dizziness, anemia and lethargy [94]. Ingestion of zinc containing tablets for six weeks, such as zinc sulfate, that contain elemental zinc up to $150 \mathrm{mg}$, causes nausea, vomiting and abdominal cramps [95]. Zinc gluconate and zinc oxide also have same effects on gastrointestinal tract [96]. 


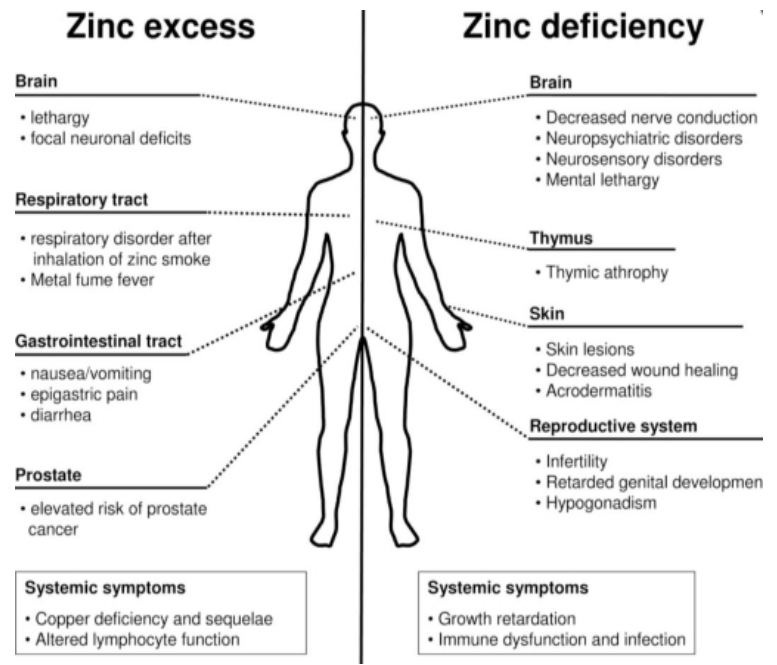

Figure 6. Comparison between effects of zinc deficiency and zinc excess [92]

Studies have shown that there is an association between copper deficiency and uptake of high zinc supplements [97]. This association is thought to be caused by combative absorption relationship of copper and zinc within the RBC's, moderated by MT. Large intake of zinc up regulates the expression of $\mathrm{MT}$, as a result of which, MT has higher affinity with copper as compared to zinc. Thus MT binds with available copper ions and the complex formed is then released [98]. Deficiency of copper includes many symptoms such as abnormal cardiac function, increased plasma cholesterol, decreased superoxide dismutase, neutropenia, leukopenia, anemia, hypocupremia and weakened iron mobilization [99].

Unlike other heavy metals, zinc is not thought to be a carcinogen. Leitzmann study has shown that there is an association between prostate cancer and intake of zinc in the form of supplements. Intake of zinc containing supplements up to $100 \mathrm{mg} /$ day didn't increase the risk of prostate cancer but the risk increases to 2.9 fold due to long term supplementation intake. This effect is not due to direct zinc carcinogenicity because incidence of cancer increases due to immunosuppression [100].

Accumulation of zinc also occurs through skin but its mechanism is not yet clearly defined.
In order to study the zinc effects on human skin, a patch of $25 \%$ zinc oxide was left on human skin for 2 days but there was no affirmation of any type of dermal irritation [101]. Another study was done on guinea pigs, rabbits and mice and in this study zinc chloride proved to be a strong irritant [102].

\section{Effects on respiratory system}

Metal fumes inhalation such as zinc oxide causes metal fume fever (MFF) [103]. It mostly occurs by inhaling zinc containing smoke produced by welding or zinc smelting [104]. Studies have found that MFF is not lethal and its effects disappear after 2-3 days. It includes many symptoms such as arthralgia, pyrexia, dyspnea and cough [105]. The major source of zinc chloride and zinc oxide is military smoke bombs. Another study has shown that 48 hour zinc chloride exposure causes a respiratory distress called 'adult respiratory distress syndrome' [106].

\section{Zinc and apoptosis}

On cellular level, zinc is involved in taking decisions of life and death regulation. In apoptosis regulation, the definite mechanism of zinc is questionable. Various studies have shown that it can be either anti-apoptotic or pro-apoptotic, depending on zinc's concentration. Its excess and deficiency both can induce apoptosis. Studies have shown that when intracellular zinc is released, it causes neural apoptosis. So, it is also involved in neurodegenerative diseases and onset of Alzheimer's disease can also occur due to deregulated homeostasis of zinc.

\section{Effects on immune system}

Intake of 200-400 mg of zinc per day can disturb the immune functioning. B-cells of pancreas have great amount of zinc as compared to other cells of the human body so, studies have found that there may be an association between diabetes and zinc. However many studies have described the role of zinc deficiency in diabetic patients but the exact mechanism is not clear yet [107]. 


\section{Effects of mercury accumulation on human health:}

Increasing industrialization is constantly adding heavy metals to the environment. Because of the potential toxicity of heavy metals to humans and animal, the scientists have focused their attention to the fate of these metals [108].

\section{Effects of mercury vapors}

Mercury vapors if inhaled at high concentrations can lead to acute bronchitis and interstitial pnuemonitis and can also adversely affect central nervous system causing tremors or increased excitability. Chronic mercury exposure can lead to serious impairments in the central nervous system. Initially the condition has nonspecific signs and is called micromercurialism or asthenic-vegetative syndrome. The clinical findings of this condition include tremors, more radioiodine uptake in the thyroid, thyroid enlargement, tachycardia, labile pulse, hematologic changes, gingivitis or increased urinary excretion of mercury. With prolonged exposure the condition may become more drastic starting from tremors of muscles performing fine motor functions like eyelids and fingers and may lead to trembling of the whole body. These changes are paralleled with personality and behavioral changes with memory loss, depression, increased excitability, delirium and even hallucinations. Two of the main features associated with mercury toxicity are gingivitis and salivation. Tremors, gingivitis and increase in excitability have been characterized as the three major symptoms of mercury toxicity resulting from inhalation of vapors of mercury [109]. Chronic exposure to mercury particularly during occupational activities can cause nephrotic syndrome and proteinuria. Mercury vapors released from dental amalgams may have potentially toxic effects on human health [110]. Mercury released from dental amalgams has been suspected to be the cause of increased urinary excretion of mercury and accumulation of mercury in organs such as the kidneys and central nervous system [111].

\section{Effects of mercuric salts}

From toxicological point of view, the best known mercuric salt is the bichloride of mercury which is a corrosive sublimate. Oral ingestion of this salt can cause severe abdominal cramps, urine suppression and diarrhea [112]. Ingestion of mercuric chloride and similar mercuric salts can cause ulcers, bleeding and necrosis of GI tract that is often followed by shocks and failure of the respiratory system. Renal failure can occur within 24 hours after ingestion due to necrosis of proximal tubular epithelium that ultimately leads to anuria, uremia and oliguria. Tubular lining can be regenerated if it is possible to maintain the patient through dialysis. These changes subsequently lead to irreversible cell damage such as mitochondrial disruption, rupture of cellular membranes and release of lysosomal enzymes. Mercuric chloride if injected can cause necrosis of the epithelium of the kidney [113]. At the cellular level the plasma membrane is disrupted along with endoplasmic reticulum and disruption of other cytoplasmic membranes also occur. Ribosomal loss, degradation of polysomes, swelling of mitochondria with formation of intramatrical deposits and chromatin condensation are other changes that may occur during necrosis of renal cells [114]. Chronic exposure to mercury salts and mercury vapours even at low levels can induce immunologic glomerular disease. Proteinuria can develop in exposed persons which is reversible if exposure is reduced [115].

\section{Effects of mercurous mercury}

Since mercurous mercury compounds are less soluble they tend to be less toxic than mercuric salts. Calomel a powder used in medicines contains mercurous chloride. It has been extensively used in teething powder for children and is now suspected to be the cause of acrodynia also known as the "pink disease". The disease occurs due to hypersensitive response of skin to mercury salts causing more sweat secretion, vasodilation and hyperkeratosis. Common symptoms in children include swelling of spleen, development of a pink colored rash, hyperkeratosis, fever and swelling of lymph nodes and fingers [116]. 


\section{Effects of methyl mercury}

Most important health effects caused by mercury are due to environmental exposure to methyl mercury. Mercury toxicity due to short term alkyls produces unique but non-specific effects. Studies about epidemics occurring in Japan and Iraq have provided information about the clinical signs and neuropathology of methyl mercury toxicity [117]. Most important human health effects due to methyl mercury exposure are neurotoxic effects [118] in adults and fetal toxicity occurring due to maternal exposure to methyl mercury [119]. Fish is the major source of exposure to methyl mercury and affects brain. Clinical manifestations include parethesia (numbness around mouth and extremities), neurasthenia (weakness, fatigue and lack of concentration), ataxia (clumsy walk and difficulty swallowing), loss of hearing, tremors, coma and eventually death. Focal necrosis of neurons in the cerebrum and cerebellum occurs and they are replaced by glial cells. in most cases cerebral edema occurs but if the degeneration of grey matter occurs constantly, cerebral atrophy may result [120]. In utero exposure of fetus to mercury can lead to abnormal migration of neurons and disorganization of brain nuclei [121].

\section{Conclusion}

The prevention from these heavy metals toxicity is necessary to maintain good health. It is necessary to identify heavy metal sources and then remove them to avoid any further disclosure. There are certain preventive actions to avoid these heavy metals direct exposure i.e. avoid dusty environment in homes as well as outside, use safe and clean water and also avoid smoky environment. There are so many preventive actions to avoid such products which contain heavy metals. It is very necessary to take various health safety measures to control and prevent heavy metals toxicity in homes, occupational level and in external environments.

\section{References}

1. A. F. Holleman and E. Wiberg, Lehebuch du Anoranischen chemie, 102 edition, Water de Gruyter, Berlin (1985).
2. H. Wintz, T. Fox and C. Vulpe, J. Environ. Bio., 26 (2005) 306.

3. A. S. Mildvan, The enzymes, Vol. 2, Academic Press, London (1970).

4. E. Nieboer and D. H. S. Richardson, Environ. Pollut., 1 (1980) 2.

5. R. K. Sharma and M. Agrawal, J. Environ. Biol., 26 (2005) 301.

6. Lenntech Water Treatment and Air Purification: Water Treatment, Lenntech, (2004).

7. A. Gore, Respect the Land, Our Precious Planet, Time Magazine, 150 (1997) 8.

8. J. O. Duruibe, M. O. C. Ogwuegbu and J. N. Egwurugwu, Int. J. Phy. Sci., 2 (2007) 112.

9. D. McCluggage, Heavy Metal Poisoning, NCS Magazine, (1991).

10. L. Järup, British Medical Bulletin, 68 (2003) 167.

https://doi.org/10.1093/bmb/ldg032

11. U. Förstner and G. T. Wittmann, Metal pollution in the aquatic environment, $2^{\text {nd }}$ Edition, Springer Science \& Business Media, (2012).

12. H. Tapiero, D. M. Townsend and K. D. Tew, Biomed. Pharmacother., 57 (2003) 386. https://doi.org/10.1016/S0753-3322(03) $00012-X$

13. L. M. Gaetke and C. K. Chow, Toxicol., 189 (2003) 147.

https://doi.org/10.1016/S0300483X(03)00159-8

14. F. M. Pizzaro, M. Olivares and R. Uauy, Environ. Health Perspect., 107 (1999) 117.

https://doi.org/10.1289/ehp.99107117

15. World Health Organization (W.H.O), IPCS Environmental Health Criteria, Copper. Geneva, (1998).

16. M. Frydman, B. Tamir and L. A. Farrer, Proc. Natl. Acad Sci. USA., 82 (1985) 1819. https://doi.org/10.1073/pnas.82.6.1819

17. R. E. Tanzi, K. Petrukhin and I. Cherov, Nat Genet, 5 (1993) 344. https://doi.org/10.1038/ng1293-344

18. H. M. Chan, L. A. Tease and H. C. Liu, Raven Press, New York, (1983) 147.

19. A. M. Pradham, I. C. Talbot and M. S. Tanner, Pediatr. Res., 17 (2000) 435.

20. S. Sethi, S. Grover and M. B. Khodaskar, Ann. Trop. Paediatr., 14 (1993) 3. 
https://doi.org/10.1080/02724936.1993.1174

$\underline{7618}$

21. L. Fewtrell, D. Kay and F. Jones, Public Health (abstr), $110 \quad$ (1996) 175. https://doi.org/10.1016/S00333506(96)80072-2

22. R. A. Goyer, Environ. Health Perspect., 86 (1990) 177.

https://doi.org/10.1289/ehp.9086177

23. Nuclear Regulatory Commission (NRC), Measuring Lead Exposure in Infants, Children and Other Sensitive Populations. Washington DC, (1993).

24. M. A. Perlstein and R. Attila, Clin. Pediatr., 5 (1966) 292.

https://doi.org/10.1177/00099228660050051 $\underline{0}$

25. N. Zahra, Asian J. Adv. Basic Sci., 2 (2014) 70.

26. N. Zahra, Pak. J. Anal. Environ. Chem., 13 (2012) 01.

27. N. Zahra, Am. J. Sci. Ind. Res., 6 (2012) 387.

28. H. L. Needleman, A. Schell and D. Bellinger, N. Engl. J. Med., 322 (1990) 82. https://doi.org/10.1056/NEJM199001113202 $\underline{03}$

29. J. Schwartz and D. Otto, Arch. Environ. Health, 46 (1991) 300. https://doi.org/10.1080/00039896.1991.9934 $\underline{391}$

30. K. N. Lindgren, V. L. Masten and D. P. Ford, Occup. Environ. Med .53 (1996) 472. https://doi.org/10.1136/oem.53.7.472

31. ATSDR, Toxicological Profile for Lead, Washington DC, (1999).

32. R. A. Goyer and T. W. Clarkson, The Basic Science of Poisons, $5^{\text {th }}$ edition, McGraw-Hill Health Professions Division, (1996)

33. T. Oliver, Lead Poisoning: From the Industrial, Medical and Social Points of View, Lewis, London (1914).

34. R. A. Goyer and B. C. Rhyne, Int. Rev. Exp. Pathol., 12 (1973) 1.

35. J. F. Moore, R. A. Goyer and M. H. Wilson, Lab. Invest., 29 (1973) 488.

36. J. R. McLachlin, R. A. Goyer and M. G. Cherian, Toxicol. Appl. Pharmacol., 56 (1980) 418. https://doi.org/10.1016/0041008X(80) 90076-9
37. J. P. Buchet, H. Roels and A. Bernard, J. Occup. Med., 22 (1980) 741.

38. J. F. Rosen, Dietary and Environmental Lead: Human Health Effects, Mahaffey K.R. (eds), Elsevier/ North-Holland, Amsterdam, (1985).

39. V. Batuman V, J. K. Maesaka and B. Haddad, N. Engl. J. Med., 304 (1981) 520.

40. W. Victery, Environ. Health Perspect., 78 (1988) 71. https://doi.org/10.1289/ehp.887871

41. M. Valentino, M. Governa and I. Marchiseppe, Arch. Toxicol, 65 (1991) 685. https://doi.org/10.1007/BF02098038

42. B. Jaremin, Bull Inst. Marit. Trop. Med. (Gdynia,) 34 (1983) 187.

43. J. P. Pounds, G. J. Long and J. F. Rosen, Environ. Health Perspect., 91 (1991) 17. https://doi.org/10.1289/ehp.919117

44. C. S. Fullmer, Neurotoxicology, 13 (1992) 799.

45. B. L. Gulson, K. R. Mahaffey and C. W. Jameson, J. Lab. Clin. Med., 131 (1998) 324. https://doi.org/10.1016/S00222143(98)90182-2

46. H. D. Stowe and R. A. Goyer, Fertil Steril, 22 (1971) 755.

https://doi.org/10.1016/S00150282(16)38586-7

47. G. Assenato, C. Pac and R. Molinini, Arch. Environ. Health, 41 (1986) 387. https://doi. org/10.1080/00039896.1986.9935784

48. M. Rodamilans, M. J. Martinez-Osaba and J. To-Figueras, Hum. Toxicol., 7 (1988) 125. https://doi.org/10.1177/09603271880070020 $\underline{3}$

49. A. J. McMichael, G. V. Vimpani and E. F. Robertson, J. Epidemiol. Commun. Health, 40 (1986) 18.

https://doi.org/10.1136/jech.40.1.18

50. N. Zahra, S. T. sheikh and K. Javed, J. Chem. Soc. Pak., 30 (2008) 797.

51. P. Trumbo, A. A. Yates, S. Schlicker and M. Poos, J. Am. Diet. Assoc., 101 (2001) 294. https://doi.org/10.1016/S00028223(01)00078-5

52. A. Bernard, Biometals, 17 (2004) 519. https://doi.org/10.1023/B:BIOM.0000045731 $\underline{.75602 . b 9}$ 
53. A. B. G. Lansdown, Food Chem. Toxicol., 29 (1991) 57. https://doi.org/10.1016/02786915(91)90063-D

54. S. V. Adams, P. A. Newcomb, M. Shafer, C. Atkinson, E. J. A. Bowles, K. M. Newton, and J. W. Lampe, Sci. Total Environ., 409 (2011) 1632.

https://doi.org/10.1016/j.scitotenv.2011.01.0 $\underline{37}$

55. Agency for Toxic Substances and Disease Registry, Toxicological Profile Information, Toxicol.Ind. Health, 11 (1995) 196.

56. Y. K. Bishak, L. Payahoo, A. Osatdrahimi, and A. Nourazarian, Asian Pac. J. Cancer. Prev., 16 (2015) 9.

https://doi.org/10.7314/APJCP.2015.16.1.9

57. D. Campen, J. Nutrition, 97 (1969) 104.

58. K. J. Chuang, K. Y. Lee, C. H. Pan, C. H. Lai, L. Y. Lin, S. C. Ho and H. C. Chuang, Food Chem. Toxicol., 93 (2016) 138. https://doi.org/10.1016/j.fct.2016.05.008

59. G. Bertin, and D. Averbeck, Biochimie, 88 (2006) 1549.

https://doi.org/10.1016/j.biochi.2006.10.001

60. S. Samman and D. C. Roberts, Med. J. Aus., 146 (1987) 246.

61. C. Devirgiliis, P. D. Zalewski, G. Perozzi and C. Murgia, Mutation Res. Fundamental and Molecular Mechanisms of Mutagenesis, 622 (2007) 84.

https://doi.org/10.1016/j.mrfmmm.2007.01.0 $\underline{13}$

62. N. Zahra and Y. N. Butt, Pak. J. Anal. Environ. Chem., 16 (2015) 1.

63. Y. H. Choi, H. Hu, B. Mukherjee, J. Miller and S. K. Park, (2012). Environ. Health Perspect., 120 (2012) 1544. https://doi.org/10.1289/ehp.1104863

64. M. A. Fernandez, P. Sanz, M. Palomar, J. Serra and E. Gadea, Occup. Med., 46 (1996) 372.

https://doi.org/10.1093/occmed/46.5.372

65. P. M. Ferraro, S. Costanzi, A. Naticchia, A. Sturniolo and G. Gambaro, BMC Public Health, 10 (2010) 1. https://doi.org/10.1186/1471-2458-10-304

66. P. R. Flanagan, J. S. McLellan, J. Haist, G. Cherian, M. J. Chamberlain and L. S. Valberg, Gastroenterology, 74 (1987) 841.
67. G. Kazantzis, Biometals, 17 (2004) 493. https://doi.org/10.1023/B:BIOM.0000045727 $.76054 . \mathrm{f3}$

68. G. F. Nordberg, Biometals, 17 (2004) 485. https://doi.org/10.1023/B:BIOM.0000045726 .75367 .85

69. G. J. Fosmire, Am. J. Clinic. Nutr., 51 (1990) 225.

70. J. Godt, F. Scheidig, C. Grosse-Siestrup, V. Esche, P. Brandenburg, A. Reich, and D. Groneberg, J. Occup. Med. Toxicoly, 1 (2006) 22.

https://doi.org/10.1186/1745-6673-1-22

71. G. Gong, K. A. Hargrave, V. Hobson and M. B. A. David M. S. Lefforge, J. Environ. Health, 74 (2011) 16.

72. H. Gunshin, B. Mackenzie, U. V. Berger, Y. Gunshin, M. F. Romero, W. F. Boron, and M. A. Hediger, Nature, 388 (1997) 482. https://doi.org/10.1038/41343

73. J. Harding, Br. J. Ophthal., 79 (1995) 199. https://doi.org/10.1136/bjo.79. 3.199

74. H. Liu-Sheng, Y. Xiao-Shan and W. DeChang, Int. J. Rad. Biol., 60 (1991) 907. https://doi.org/10.1080/09553009114552711

75. J. E. Heck, Y. Chen, V. R. Grann, V. Slavkovich, F. Parvez and H. Ahsan, J. Occup. Environ. Med., 50 (2008) 80. https://doi.org/10.1097/JOM.0b013e31815ae 9d4

76. J. E. Heck, Y. Chen, V. R. Grann, V. Slavkovich, F. Parvez and H. Ahsan, J. Occup. Environ. Med., 50 (2008) 80. https://doi.org/10.1097/JOM.0b013e31815ae $\underline{9 \mathrm{~d} 4}$

77. N. Zahra, J. Chem. Soc. Pak., 32 (2010) 259.

78. S. Homma, R. Jones, J. Qvist, W. M. Zapol and L. Reid, Hum. Path., 23 (1992) 45. https://doi.org/10.1016/00468177(92)90010-Z

79. M. R. Islam, I. Khan, S. M. N. Hassan, M. McEvoy, C. D'Este, J. Attia and A.H. Milton, Environ. Health, 11 (2012) 1. https://doi.org/10.1186/1476-069X-11-38

80. L. Järup, M. Berglund, C. G. Elinder, G. Nordberg and M. Vanter, Scand. J. Work Environ. Health, (1998) 1.

81. T. Jin, M. Nordberg, W. Frech, X. Dumont, A. Bernard, T. T. Ye and Y. Li, Biometals, 15 (2002) 397. 
https://doi.org/10.1023/A:1020229923095

82. G. Kazantzis, Environ. Health Perspect., 28 (1979) 155.

83. Y. H. Kim, E. Y. Kim, B. J. Gwag, S. Sohn and J. Y. Koh, Neuroscience, 89 (1999) 175. https://doi.org/10.1016/S03064522(98)00313-3

84. C. F. Mills, Zinc in Human Biology. ILSI Human Nutr. Rev., (1998).

85. R. Lauwerys, J. P. Buchet, H. Roels and A. Bernard, Toxicological European Res. Recherche Europeenne en Toxicologie, 4 (1982) 7.

86. M. F. Leitzmann, M. J. Stampfer, K. Wu, G. A. Colditz, W. C. Willett and E. L. Giovannucci, J. Natl. Cancer Inst., 95 (2003) 1004. https://doi.org/10.1093/jnci /95.13.1004

87. S. M. Mosad, A. A. Ghanem, H. M. ElFallal, A. M. El-Kannishy, A. A. El Baiomy, A. M. Al-Diasty and L. F. Arafa, Current Eye Res., 35 (2010) 23. https://doi.org/10.3109/02713680903362880

88. M. S. Ågren, Dermatology, 180 (1990) 36. https://doi.org/10.1159/000247982

89. G. Nordberg, T. Jin, X. Wu, J. Lu, L. Chen, Y. Liang and M. Nordberg, J. Trace Elem. Med. Biol., 26 (2012) 197. https://doi.org/10.1016/j.jtemb.2012.03.007

90. G. F. Nordberg, T. Jin, X. Wu, J. Lu, L. Chen, L. Lei and M. Nordberg, Biochimie, 91 (2009) 1282.

https://doi.org/10.1016/j.biochi.2009.06.014

91. S. E. O'Bryant, M. Edwards, C. V. Menon, G. Gong and R. Barber, Int. J. Environ. Res. Public Health, 8 (2011) 861. https://doi.org/10.3390/ijerph8030861

92. T. Ogiso, Chem. Pharm. Bull., 22 (1974) 55. https://doi.org/10.1248/cpb.22.55

93. T. Ogiso, Chem. Pharm. Bull., 27 (1979) 515. https://doi.org/10.1248/cpb.27.515

94. P. Joseph, Toxicol. Appl. Pharmacol., 238 (2009) 272. https://doi.org/10.1016/j.taap.2009.01.011

95. B. Panda and B. Panda, Int. J. Ecosystem, 5 (2015) 75.

96. L. Plum, L. Rink and H. Haase, Int.J. Environ. Res. Public Health, 7 (2010) 1342. https://doi.org/10.3390/ijerph7041342
97. Radioaktivität der Umwelt in der Schweiz, Friborg, Suisse, Environ. Int., 19 (1993).

98. M. Rodríguez-Barranco, M. Lacasaña, C. Aguilar-Garduño, J. Alguacil, F. Gil, B. González-Alzaga and A. Rojas-García, Sci. Total Environ., 454 (2010) 562.

99. P. Saeed Dastgiri, J. Health Pop. Nutr., 28 (2010) 14.

100. P. Tchounwou, A. Patlolla and J. Centeno, Toxicol. Pathol., 31 (2003) 575.

101. A. Q. Truong-Tran, J. Carter, R. E. Ruffin and P. D. Zalewski, Biometals, 14 (2001) 315. https://doi.org/10.1023/A:1012993017026

102. J. Y. Barbee Jr and T. S. Prince, Southern Medical Journal, 92 (1999) 510. https://doi.org/10.1097/00007611199905000-00012

103. C. R. Tyler and A. M. Allan, Current Environ. Health Reports, 1 (2014) 132. https://doi.org/10.1007/s40572-014-0012-1

104. B. L. Vallee and K. H. Falchuk, Physiol. Rev., 73 (1993) 79.

105. C. Vogelmeier, K. Bencze and G. Fruhmann, CHEST J., 92 (1987) 946. https://doi.org/10.1378/chest.92.5.946

106. M. E. Wastney, R. L. Aamodt, W. F. Rumble and R. I. Henkin, Am. J. PhysiologyRegulatory, Integrative and Comparative Physiology, 251 (1986) R398.

107. A. Fukunaka and Y. Fujitani, Jap. J. Clin. Med., 74 (2016) 1132.

108. J. L. Brown, The British journal of radiology, 61 (1988) 327. https://doi.org/10.1259/0007-1285-61-724$\underline{327}$

109. S. Naeem, N. Zahra, U. Zafar and S. Munawar, J. Sci. Ind. Res., 44 (2009) 403.

110. L. J. Goldwater, Mercury: A History of Quicksilver, York Press, Baltimore (1972).

111. G. M. Richardson, M. Mitchell and S. Coad, Water Air Soil Pollut J., 80 (1995) 21.

112. T. W. Clarkson, L. Friberg and J. B. Hursh, Biological Monitoring of Toxic Metals, Plenum Press, New York (1988).

113. T. L. Gritzka and B. F. Trump, Am. J. Pathol, 52 (1968) 1225.

114. H. Roels, J. P. Gennart and R. Lauwerys, Am. J. Ind. Med., 7 (1985) 45. https://doi.org/10.1002/ajim.4700070106 
115. G. A. Henry, B. M. Jarnot and M. M. Steinhoff, Clin Immunol Immunopathol, 49 (1988) 187.

https://doi.org/10.1016/00901229(88)90109-2

116. D. S. Matheson, T. W. Clarkson and E. W. Gelfand, J. Pediatr., 97 (1980) 153.

https://doi.org/10.1016/S00223476(80)80159-4

117. M. Berlin, Handbook on the Toxicology of Metals, $2^{\text {nd }}$ edition, Vol. 2, Elsevier, Amsterdam (1986).
118. F. Bakir, S. F. Damluji and L. Amin-Zaki, Science, 181 (1973) 230. https://doi.org/10.1126/science.181.4096.230

119. C. Cox, T. W. Clarkson and D. O. Marsh, Environ. Res. 49 (1989) 318. https://doi.org/10.1016/S00139351(89)80075-1

120. T. Takeuchi, Neurotoxicology, Raven Press, New York (1977).

121. P. R. Sager, M. Aschner and P. M. Rodier, Dev. Brain Res., 12 (1984) 1. https://doi.org/10.1016/0165$\underline{3806(84) 90170-6}$ 